\title{
Qualidade Total, Saúde e Trabalho: Uma Análise em Empresas Sucroalcooleiras Paulistas
}

\author{
Rosemeire Aparecida Scopinho
}

\section{ResUMO}

Entre os assalariados rurais canavieiros predominam concepções e práticas em saúde de natureza individual, biologicista e curativa. O artigo analisa a política de gestão de recursos humanos no setor sucroalcooleiro paulista, procurando refletir sobre as suas implicações para os trabalhadores, no que se refere à compreensão da saúde-doença como processo bio-psicossocial e um direito básico de cidadania. A análise focaliza o processo de reestruturação produtiva em curso no setor, que se vale de um conjunto de inovações tecnico-organizacionais, especialmente na implantação dos programas que visam à qualidade total, como estratégias gerenciais para obter aumento de produtividade, melhora na qualidade e redução dos custos de produção. A política de gestão de recursos humanos, aparentemente humanista e participativa, não supera os mais tradicionais métodos de gestão do trabalho, não se traduz em melhorias reais na qualidade de vida, e ainda contribui para dificultar o processo organizativo dos trabalhadores. As práticas empresariais em saúde e formação de recursos humanos objetivam o controle e adequação do trabalho às exigências de produtividade e qualidade.

Palavras-chaves: organização do trabalho; qualidade total; saúde; segurança no trabalho.

\begin{abstract}
Among rural sugar cane wage earners the predominant conceptions and uniform practices in health are of an individual, biologicist and curative nature. This paper analyses the human resource administrative policy, in an attempt to think upon its implications for the workers, inasmuch as it refers to the understanding of health-illness as a bio-psycho-social process and a basic right of citizenship. The reflection is carried out having as a background the productive restructuration process in progress in the sector, which comprises a set of technical-organisational innovations, especially those concerning the implementation of the total quality programmes as managing strategies to obtain productivity, quality and a reduction in the cost of production. Although the policy for administration of human resources incorporates a humanistic and participatory speech, it does not represent an attitude that outdoes the most traditional methods in work administration. It does not manifest itself in real improvements in the quality of life, and also contributes to making more difficult the worker's organising process. The business practices in health and human resource training, are more linked to work control and its adequacy to quality and productivity needs.
\end{abstract}

Key words: work organization; total quality; health; safety at work. 


\section{INTRODUÇĀO}

Este artigo procura refletir sobre a relação entre introdução de inovações organizacionais, mais especificamente a implantação dos programas de gestão empresarial que visam à qualidade total, e a saúde e segurança no trabalho no setor sucroalcooleiro.

Estudos realizados anteriormente apontam que o padrão de adoecimento do trabalhador rural canavieiro está estreitamente relacionado com o modo de organização e de realização do seu trabalho. Apesar de ser a saúde um requisito fundamental para a realização do trabalho na lavoura canavieira e dos avanços organizativos da categoria a partir de meados da década de oitenta, entre esses trabalhadores predominam concepções e práticas em saúde de natureza individual, biologicista e curativa que tendem a reproduzir o modelo de atenção à saúde predominante na grande maioria dos serviços de saúde, públicos e privados. Há inúmeras dificuldades para mobilizar e organizar a categoria para tratar esta como uma questão que é também de natureza econômica e social e um direito básico de cidadania (Alessi e Scopinho, 1994; Scopinho e Valarelli, 1995; Scopinho, 1995; Scopinho et al., 1999).

Esta problemática relativa à saúde e segurança do trabalhador canavieiro ocorre dentro do contexto de grandes e profundas transformações por que passa a economia sucroalcooleira na década de noventa. Este setor, a exemplo de outros, reestrutura-se inovando a base técnica e os modos de gestão organizacional para tentar sobreviver e ampliar-se nos competitivos mercados da era da globalização. Nosso objetivo neste artigo é o de analisar as inovações que estão sendo feitas na política de gestão de recursos humanos dessas empresas, procurando compreender os seus impactos para os trabalhadores, especialmente a sua contribuição para formar a consciência sanitária individual, biologicista e curativa predominante entre eles.

Parte-se do pressuposto de que a saúde-doença é também um processo social, porque está direta ou indiretamente relacionado às condições de vida e trabalho dos indivíduos, e que os trabalhadores organizados também são sujeitos ativos nos processos de investigação e de construção do conhecimento sobre a saúde e a segurança no trabalho. Os trabalhadores tanto podem adoecer de forma genérica, dependendo do espaço e do tempo histórico em que eles vivem, como também de modo específico, dependendo do modo como se organiza e realiza o trabalho que eles executam para sobreviver (Laurel e Noriega, 1989). No contexto das rela- 
ções sociais de produção existe um processo pedagógico que procura adaptar, do ponto de vista técnico e comportamental, o trabalho às necessidades do capital. É uma pedagogia que, por um lado, procura educar o trabalhador para adaptar-se a um determinado modo de divisão e organização do trabalho; mas, por outro, pode também contribuir para desenvolver a consciência da necessidade de transformar as condições em que se realiza o trabalho como item fundamental da melhoria das condições de vida e saúde dos trabalhadores. Neste processo pedagógico, a política, os programas, as estratégias de gestão e os agentes de recursos humanos são considerados instrumentos gerenciais privilegiados de controle e adequação do trabalho às exigências do processo produtivo (Kuenzer, 1989; Machado, 1994).

Procura-se demonstrar que, no contexto da reestruturação produtiva em curso no setor, por um lado, a gestão dos recursos humanos assume importância cada vez maior para as empresas atingirem os objetivos de aumento de produtividade e qualidade com redução de custos de produção. Por outro lado, a política de gestão, apesar de ser aparentemente humanista e participativa, na prática não supera os mais tradicionais métodos de gestão do trabalho; não significa melhorias reais na qualidade de vida e ainda contribui para dificultar o processo organizativo dos trabalhadores.

A análise baseia-se em estudos realizados em três empresas localizadas no interior do Estado de São Paulo no período de 1994 a 1998. Duas empresas foram selecionadas por serem as que apresentavam maior capacidade de moagem de cana (primeira e terceira no ranking paulista, segundo o GPA [1994]). Uma dessas duas empresas localiza-se na macrorregião canavieira de Ribeirão Preto ${ }^{(1)}$. A terceira usina também localiza-se na referida região e é a oitava colocada no ranking de moagem de cana. As unidades foram selecionadas também por estarem na vanguarda na implantação dos sistemas de gestão pela qualidade total. Na macrorregião de Ribeirão Preto situa-se o maior e mais moderno parque sucroalcooleiro de São Paulo e do país. Na safra 98/99 a referida região possuia 46 unidade produtivas, correspondentes a 34\% do Estado de São Paulo. Essas unidades moeram 85.533 .755 toneladas de cana ( $43 \%$ do total de cana moída no Estado), produzindo 113.206 .435 sacas de $50 \mathrm{~kg}$ de açúcar (48\% do total de sacas produzidas no Estado), 3.721.804.260 litros de álcool (41\% do total de litros produzidos no Estado), e gerando 58.884 empregos diretos, o que representa 34\% dos empregos diretos gerados pelo setor no Estado de São Paulo (Anuário Jornalcana, 1999).

Os dados foram coletados em entrevistas semi-estruturadas com gestores, trabalhadores e sindicalistas e também na participação em seminários, feiras e eventos promovidos por universidades, empresas e outras organizações interessadas em debater a problemática sócio-ambiental relacionada ao setor, no contexto de uma possível reativação do Proálcool. 


\section{Tecnologia e Trabalho}

Em meados dos anos 80, iniciou-se nova fase do processo de reestruturação produtiva no setor sucroalcooleiro no Brasil. Por um lado, sob a influência neoliberalista, o Estado deixou de regular mais diretamente a economia sucroalcooleira; o corte dos subsídios e dos programas de incentivo à produção e comercialização obrigou-a a disputar espaços nos mercados internos e externos, cada vez mais competitivos nesses tempos de globalização da economia. Por outro lado, os movimentos sociais reagiram mais enfaticamente contra os abusos que vêm sendo praticados pelas empresas sucroalcooleiras, principalmente no que se refere à exploração do meio ambiente e dos trabalhadores.

Mas, apesar da desregulamentação, a reestruturação ainda tem sido amparada pelo Estado, por meio do sistema público de Pesquisa e Desenvolvimento, do reescalonamento das dívidas dos usineiros para com os órgãos públicos, da oferta de novas modalidades de créditos e de subsídios e do reaquecimento do complexo agroindustrial canavieiro, com a implementação de projetos de co-geração de energia elétrica, por exemplo.

A reestruturação atinge a todos os setores da agroindústria sucroalcooleira (rural, industrial e administrativo) e é sustentada pela necessidade de incrementar a produtividade, de aprimorar a qualidade e de reduzir custos. Caracteriza-se pela crescente introdução de inovações na base técnica: a mecanização de todas as fases do ciclo produtivo agrícola, o uso de novos produtos químicos, da informática e da automação microeletrônica no controle do processo industrial; pela diversificação da produção agrícola e industrial, pelo rigor na implantação dos sistemas de controle de qualidade, pela terceirização de determinadas etapas da produção e pelo redirecionamento das políticas de recursos humanos (Scopinho, 1995). A reestruturação, sem dúvida, vem contribuindo para tornar os empresários mais aptos para enfrentarem as novas regras de competição do mercado. Entretanto, para os trabalhadores, ela vem gerando inúmeros impactos negativos, principalmente do ponto de vista sócio-ambiental, destacando-se entre eles o aumento do desemprego tecnológico (Veiga Filho et al., 1994), a queda no valor real dos salários (Nogueira, 1992) e uma sensível piora na qualidade das relações e condições de trabalho (Scopinho, 1995; Scopinho e Valarelli, 1995; Eid et al., 1998; Scopinho et al., 1999).

No setor rural, a modernização expressa-se em todas as fases do ciclo produtivo por meio das inovações biológicas, químicas e físicas. Utilizadas em conjunto, essas inovações potenciam e aceleram a mecanização da base técnica e condicionam novas formas de dividir e organizar o trabalho (Alves, 1992). No que se 
refere às relações de trabalho se, por um lado, a mecanização do corte da cana coloca uma tendência de estabilização do número de contratações nos períodos de safra e entressafra (Cortéz, 1993), por outro lado, contraditoriamente, é crescente o processo de subcontratação da mão-de-obra rural. Nos momentos de pico da atividade agrícola, as usinas recrutam trabalhadores temporários por meio das empreiteiras que, na maioria das vezes, são pequenas empresas ilegais, do tipo doméstico, sonegadoras de encargos trabalhistas e onde predominam as relações informais de trabalho.

Quanto às condições de trabalho, sabe-se que os ambientes industriais e as frentes de trabalho rural das usinas e destilarias caracterizam-se pela insalubridade, periculosidade e penosidade (Pinheiro, 1992; Alessi e Scopinho, 1994). Porém as novas tecnologias não têm contribuído, efetivamente, para saneá-los e melhorar as condições de saúde e de vida dos trabalhadores. Pelo contrário, o modo pelo qual essas novas tecnologias estão sendo introduzidas traz conseqüências negativas, tanto dentro como fora do espaço da produção.

Conforme verificaram Scopinho et al. (1999), a introdução da colhedeira mecânica no corte da cana-de-açúcar não diminui as cargas de trabalho do tipo físico, químico e mecânico existentes no ambiente de trabalho e ainda acentua a presença de elementos que configuram as cargas do tipo fisiológico e psíquico, porque intensificam o ritmo de trabalho. Por exemplo, as jornadas de trabalho dos operadores de máquinas agrícolas variam de 12 até 24 horas, durante a safra. O trabalho no corte mecanizado da cana é organizado em turnos de 8 ou 12 horas e, na época do revezamento, a jornada estende-se até 24 horas de trabalho, com pequenas pausas para descanso e para fazer as refeições no próprio local de trabalho.

Castigados pelas condições do ambiente de trabalho e ameaçados pelo desemprego, na maioria das vezes, os trabalhadores enfrentam as conseqüências negativas da modernização por meio de práticas de natureza individual, haja vista que a greve não tem sido uma estratégia sindical adequada para enfrentar as suas problemáticas trabalhistas e sociais. A mecanização da colheita não é apenas uma opção tecnológica; é também uma opção política, uma reação empresarial às conquistas político-organizativas obtidas pelos trabalhadores na década de oitenta. Com relação à saúde e segurança no trabalho, essas práticas individuais consistem, por exemplo, na procura de assistência médica e no exercício da automedicação como as únicas formas de tratar da saúde. Até porque afastar-se temporariamente do trabalho para consultar o médico é uma das formas possíveis que o trabalhador encontra para recuperar-se do desgaste, nem sempre de uma doença diagnosticável, provocado pela realização intensiva das atividades, com prejuízo mínimo do seu salário. 
Para as empresas, isto significa aumento nos índices de absenteísmo e de rotatividade, o que interfere no rendimento e na qualidade do trabalho. E como, apesar do aparato tecnológico disponível, elas ainda não prescindem do trabalho humano, as estratégias de gestão são redefinidas para melhor adequá-lo às atuais exigências do processo produtivo da cana, do açúcar e do álcool, no que se refere à produtividade, à qualidade e à redução dos custos de produção.

Na seqüência, discute-se a política de gestão de recursos humanos do setor sucroalcooleiro e as suas implicações para os trabalhadores, no que se refere à saúde e segurança no trabalho.

\section{Controle da qualidade e Controle do Trabalho}

Se, do ponto de vista dos assalariados rurais, as inovações tecnológicas afetam negativamente o mercado de trabalho e deterioram as relações e as condições de trabalho, trazendo-lhes sérias conseqüências sociais, do ponto de vista dos empresários elas significam investimentos de capital, cujo retorno depende, grandemente, do consentimento e da adaptação dos trabalhadores à base técnica transformada e da garantia de certas condições de reprodução que aumentem a produtividade do trabalho vivo. Com as inovações introduzidas na base técnica, o processo produtivo da cana, do açúcar e do álcool passou a exigir um tipo de trabalhador, cuja característica principal do perfil é ser, de um lado, tecnicamente experiente, qualificado e polivalente e, de outro, pessoalmente comprometido com os objetivos empresariais de produzir com qualidade e baixo custo. A construção e aperfeiçoamento constante deste perfil de trabalhador é o grande desafio para os agentes de recursos humanos nas usinas-destilarias.

Neste sentido, outro aspecto da modernização sucroalcooleira é exatamente aquele que se refere à reestruturação administrativa. Nas usinas, antes caracterizadas por um modelo de gestão burocrático e baseado na figura autoritária e centralizadora do usineiro, desenvolve-se uma estrutura gerencial ocupada, fundamentalmente, em formular e implementar uma política capaz de criar as condições ideais para a introdução das inovações tecnológicas, racionalizar o uso do trabalho humano necessário à produção e incrementar a produtividade dos trabalhadores. Os empresários e as equipes encarregadas do gerenciamento dos recursos humanos justificam a existência da política, valendo-se de argumentos centrados na melhoria da qualidade de vida dos trabalhadores, principalmente dos assalariados rurais. Isto porque, na região de Ribeirão Preto, não é de hoje que a situação social do bóia-fria tem chamado a atenção da sociedade civil, havendo inúmeros estu- 
dos que demonstram claramente as suas dificuldades de reprodução social (D'Incao, 1984; Ferrante, 1991; Alves, 1992; Pinheiro, 1992; Alessi e Scopinho, 1994; Scopinho e Valarelli, 1995; Scopinho, 1995; Scopinho et al., 1999).

De fato, parece que não é bem esta a preocupação das empresas. Por trás de uma concepção humanista e participativa de gestão de recursos humanos estão os objetivos estratégicos das usinas-destilarias: de um lado, legitimar a reestruturação produtiva junto à opinião pública e, de outro, garantir aos trabalhadores as condições mínimas de reprodução social. Desta forma, a política de recursos humanos tanto pode ser instrumento de controle dos índices de rotatividade e absenteísmo, como também veículo de formação de uma imagem de utilidade social das empresas, que gera empregos e garante assistência social aos trabalhadores, imagem importante para quem atualmente disputa espaços no mercado internacional.

Segundo Alves (1992), ao longo das últimas décadas, a crescente modernização da agricultura canavieira da região de Ribeirão Preto transformou os processos de trabalho, prescrevendo-lhes novas formas de divisão e de organização social, fundamentadas no paradigma taylorista/fordista. Entretanto, assim como o progresso técnico encontrou várias barreiras para o seu desenvolvimento, o referido paradigma também encontrou limites para generalizar-se na agricultura canavieira. Cortéz (1993) afirma que, com a mecanização de todas as fases do ciclo produtivo da cana, o número de trabalhadores contratados para os períodos de safra e entre-safra tende a estabilizar-se, o que contribui para fortalecer o padrão de organização do trabalho taylorista-fordista e faz surgir nas lavouras de cana um trabalhador rural do tipo polivalente.

Do ponto de vista da administração dos recursos humanos, autores como Alves (1992), Cortéz (1993) e Eid (1994) apontam a emergência de "novos modelos de gestão" ou "novas relações de trabalho" como uma das conseqüências da modernização tecnológica. Concorda-se com os referidos autores quanto ao fato de estar havendo mudanças nos modos de gestão do trabalho; entretanto a análise de alguns casos mostra que o atual modelo de gestão não tem nada de novo. No próximo tópico, veremos que ele se baseia nas práticas assistencial-paternalistas dos Programas de Assistência Social (PAS) e na burocracia dos departamentos de pessoal, aprimora e reorganiza a aplicação dos princípios e das técnicas do modelo taylorista/fordista e da Escola de Relações Humanas, atualizando-as e combinando-as com as técnicas do denominado modelo japonês de gestão do trabalho (Hirata, 1993) como, por exemplo, o programa de qualidade total e o programa 5S. 


\section{Da Assistência Social a Qualidade Total}

A preocupação formal com a gestão do trabalho na agroindústria canavieira surgiu na década de quarenta, com a promulgação do Estatuto da Lavoura Canavieira (ELC, decreto-lei no. 3.855 de 1941), que continha alguns dispositivos que tratavam da assistência trabalhista e social dos trabalhadores. Cabral (1990) analisa os dispositivos legais que implantaram a assistência social na agroindústria canavieira, mostrando que foi no contexto das crises econômicas vividas pelo setor que se criou uma legislação social fortemente revestida de um caráter assistencial-paternalista. No conjunto da legislação que regulava a participação do setor na economia nacional, Cabral (1990) destaca a lei 4870, aprovada em 1965, que previa a aplicação de $1 \%$ do valor da produção de cana e de açúcar e $2 \%$ da produção de álcool em Programas de Assistência Social (PAS), sujeitos ao controle do Estado. Ao analisar o caso de uma usina-destilaria da região de Ribeirão Preto, a autora concluiu que a assistência social é prática instituída, permanente e importante elemento da política de recursos humanos do setor. Para a empresa estudada por Cabral (1990), a política funcionava como meio de atrair mão-deobra na época da safra e, para os trabalhadores, ela significava salário indireto, meio de acesso a determinados bens de consumo coletivo como moradia e assistência médica, por exemplo.

No contexto da reestruturação produtiva, a atual política de recursos humanos situa-se no espaço de fusão das tradicionais práticas burocráticas e autoritárias do departamento de pessoal com aquelas paternalistas da assistência social legalmente instituída, tendendo a migrar da forma burocrática para a forma dita participativa. Tal fusão é o resultado de um esforço gerencial, tanto para adaptar as empresas às novas formas de produção e circulação, impostas pelas transformações da economia mundial, como também para atender aos reclamos da sociedade regional sobre a questão social do bóia-fria.

Almejando cientificidade, a política de recursos humanos embasa-se no modelo de gestão proposto pela Escola de Relações Humanas ${ }^{(2)}$ e, mais recentemente, em função da intensificação das transformações econômico-sociais e da competividade como fator de sobrevivência das organizações industriais nos mercados regidos pela lógica da globalização, incorpora-se a esses princípios gerais a idéia de que a gerência de recursos humanos deve comandar a implantação de programas de qualidade total, sobretudo para sensibilizar e criar nos trabalhadores atitudes em prol da produtividade com qualidade.

Atualmente, o binômio qualidade-produtividade é a base da competitividade, um imperativo categórico de sobrevivência das empresas nos mercados. Se, por um lado, a idéia de qualidade sugere funcionamento empresarial com maior pro- 
dutividade e menor custo, por outro lado, ela está associada à idéia de melhoria da totalidade do processo organizacional, principalmente do trabalho humano, e não apenas do produto. É qualidade de produto; mas, sobretudo, é qualidade de gestão do processo produtivo. Nesta direção, o essencial dos programas de gestão que visam à qualidade total é o aperfeiçoamento contínuo dos métodos e tipos de gerenciamento empresarial, que devem considerar, acima de tudo, a satisfação do cliente. Entende-se que o cliente não é apenas aquele que usufrui do produto, mas também aquele que o produz, direta ou indiretamente, o que inclui a gestão dos recursos humanos como questão estratégica para as empresas.

Machado (1994) considera que os métodos de gerenciamento da qualidade total estão sendo implantados para tornar mais eficaz o controle gerencial sobre a organização, porque eles envolvem todas as suas áreas e requerem confiabilidade e agilidade nos fluxos de informação. Representam também um fortalecimento dos mecanismos de integração organizacional, porque procuram padronizar procedimentos e condutas de modo a envolver e integrar todas as instâncias organizacionais, para aperfeiçoar continuamente o funcionamento da empresa no sentido de servir, amplamente, à sociedade. Para a autora, esses métodos gerenciais representam uma "intervenção pedagógica do capital", que visa a motivar e envolver a todos em um processo de mudança cultural e comportamental - a "cultura do controle". Machado (1994) considera que esta forma de gerenciar recursos humanos, cujo "verdadeiro fio condutor" é o controle, é uma continuidade do movimento iniciado com a Escola de Relações Humanas.

No setor sucroalcooleiro, a busca de qualidade vem reestruturando continuamente o modo de organização das empresas como um todo, especialmente a administração dos recursos humanos. Uma das principais estratégias é a racionalização do uso desses recursos, pela introdução de novas tecnologias e da terceirização de etapas intermediárias da produção. A gestão do trabalho indispensável é feita por meio de uma política que procura veicular os valores e normas necessários à expansão sucroalcooleira, ou seja, a integração entre a agricultura, a indústria e a administração, visando à cooperação e ao envolvimento dos trabalhadores com os objetivos e metas organizacionais.

Os gestores apresentam a política de benefícios sociais como sendo descentralizada e abrangente, pois são oferecidos serviços assistenciais nas áreas de saúde, educação, transporte e habitação, até empréstimos pessoais e equipamentos de lazer. Enfatiza-se a universalidade da política, procurando passar a idéia de que é cada vez mais tênue a linha divisória que separa os trabalhadores rurais dos da indústria, que todos constituem uma única família, com direitos e deveres iguais, unidos pelo ideário empresarial de vencer pelo esforço e pela dedicação. À primeira vista, fica a impressão de que a política de benefícios sociais é dádiva 
desinteressada, cuidadosamente formulada para atender aos anseios e às necessidades de todos os trabalhadores, sem distinção. Esta é a imagem que as empresas procuram passar para os trabalhadores e para a sociedade em geral: a imagem de humanismo dos seus dirigentes e de utilidade social da organização que, além de gerar muitos empregos, ainda oferece aos empregados a assistência que, infelizmente, o Estado brasileiro nega ou negligencia à população.

Entretanto, observa-se que alguns serviços, como transporte, assistência médica, são oferecidos como benefícios, mas, na verdade, trata-se do cumprimento de direitos já conquistados em lei ou nos acordos coletivos de trabalho. A assistência médica, geralmente, é oferecida em convênios com grupos de medicina privada e a contribuição do trabalhador é compulsória, mediante desconto em folha de pagamento. Ela é apresentada aos trabalhadores como um benefício; na realidade, não passa de um direito trabalhista previsto na legislação. O Serviço Especializado de Saúde e Medicina do Trabalho (SESMT), constituído pelas empresas, atende exclusivamente emergências, acidentes do trabalho, exames clínicos e laboratoriais de admissão, periódicos e demissionais, servindo como importante componente do processo de seleção dos trabalhadores e no controle dos índices de rotatividade e de absenteísmo.

Enquanto o índice de absenteísmo no setor administrativo dessas empresas é de $1 \%$, aproximadamente, no setor rural ele ultrapassa a marca de $11 \%$, sendo que a maior parte das faltas é justificada via apresentação de atestado médico. Para inibir o absenteísmo, uma usina convenceu os sindicatos de trabalhadores rurais a introduzirem uma cláusula no acordo coletivo de trabalho que os proíbe de oferecer assistência médica como serviço aos seus associados, por ser esta uma importante fonte de justificativas de faltas ao trabalho.

Quanto à universalidade da política de benefícios sociais das empresas, observa-se que nem todos os benefícios são extensivos aos trabalhadores rurais. Geralmente, benefícios como alimentação, habitação, lazer, são exclusividade dos industriários e dos trabalhadores do setor administrativo. Por exemplo, fica claro que o benefício de moradia existe em função das necessidades das empresas e não das necessidades dos trabalhadores, pois somente têm acesso à moradia na vila residencial das usinas os chefes e funcionários indispensáveis à manutenção do funcionamento ótimo e ininterrupto da empresa.

Apesar de afirmarem que a política de assistência social tem caráter universal, os assistentes sociais confessam que a demanda pelos diferentes tipos de benefício ocorre conforme as condições socioculturais do trabalhador. As solicitações dos rurícolas restringem-se, predominantemente, aos benefícios mais essenciais e acessíveis como assistência médica, farmacêutica e odontológica; este último somente para procedimentos simples como extração, prótese e restauração. Também é 
grande a demanda por gêneros alimentícios básicos, não havendo procura por bolsas de estudo e assistência psicológica, por exemplo. Os critérios de concessão dos benefícios assistenciais são estabelecidos e utilizados exclusivamente pelos agentes de recursos humanos. $\mathrm{O}$ trabalhador, apesar de arcar com parte das despesas requeridas para a manutenção da política de benefícios, não participa dessas decisões. Apenas recebe os benefícios como dádivas, como prêmios pelo bom comportamento demonstrado. Além disso, os critérios de concessão funcionam como mecanismo de regulação do consumo de produtos e serviços sociais. Ao serem implantados critérios economicamente inatingíveis, os benefícios mais caros deixam de ser requisitados pelos trabalhadores com menor poder aquisitivo, que são os que mais necessitam deles. Como vemos, na prática definitivamente cai por terra o princípio da não distinção ou da integração agricultura-indústriaadministração que, ideologicamente, veicula a política de benefícios sociais.

Devido às grandes extensões territoriais necessárias à produção sucroalcooleira, a descentralização dos serviços assistenciais é importante. Mas, se, por um lado, a descentralização realmente facilita o acesso dos trabalhadores contratados em outros municípios aos serviços e equipamentos sociais disponíveis, por outro lado também aumenta o poder de controle dos agentes de recursos humanos sobre os trabalhadores. Nas grandes usinas, além de ser descentralizado, o atendimento das assistentes sociais é personalizado e ininterrupto, contando com esquema de plantão como se fosse um pronto socorro social. Freqüentemente faz parte da rotina dos assistentes sociais a realização de visitas domiciliares para realizar avaliações sócio-econômicas das famílias, investigar as causas do absenteísmo e das ausências injustificadas no âmbito da vida pessoal ou familiar do trabalhador ou, simplesmente, levar o apoio e a solidariedade da empresa àqueles que foram vítimas de infortúnios. Desta forma, por um lado, os agentes acompanham de perto o cotidiano das famílias e podem antecipar-se no atendimento das suas necessidades, quando for conveniente para a empresa. Por outro lado, esta é uma prática paternalista que reforça a dependência do trabalhador. Mas, por sua vez, o comportamento dependente do trabalhador é importante para a empresa, porque indica que o sistema de controle sobre eles é eficiente.

Em suma, a política de benefícios sociais do setor sucroalcooleiro continua sendo, essencialmente, um instrumento gerencial de combate à rotatividade, de fixação do trabalhador na empresa. Para os trabalhadores, ela representa salário indireto e gratificação diferencial, conforme já observou Cabral (1990). No atual contexto de incertezas quanto ao emprego e ao salário, a política torna-se, cada vez mais, um importante mecanismo de controle e de regulação do comportamento político dos trabalhadores, na medida em que os benefícios são concedidos somente àqueles que aderem à ideologia empresarial de produtividade e qualidade. 
Apesar de concentrar benefícios na área da saúde, a política de recursos humanos também inclui o desenvolvimento de programas e atividades de lazer. As usinas, geralmente, contam com boa infra-estrutura para o desenvolvimento de atividades festivas, de lazer e esportivas, que são cuidadosamente planejadas para difundir valores como os de integração e espírito de equipe, mediante a atividade lúdica. Disputas esportivas entre seções, bailes, festejos e cultos religiosos comemorativos no início e no final da safra, com a participação dos familiares e da comunidade etc, são rituais que se repetem ano a ano. Eles expressam a preocupação de organizar os trabalhadores para a cooperação, de promover a integração por meio da instalação da competição sadia e controlada por regras disciplinadoras para que não chegue a ser demasiadamente conflituosa.

No geral, predomina um distanciamento entre as diretrizes da política e as práticas dos agentes de recursos humanos. A análise do percurso realizado pelo bóiafria ao ser contratado, mediante os principais programas técnicos de recursos humanos, contribuiu para demonstrar a distância.

Os programas que envolvem o trabalhador rural são, basicamente, de recrutamento e seleção de pessoal, de treinamento, de segurança e medicina do trabalho e de serviço social. Tais programas desenvolvem-se organicamente articulados e orientam-se por um sistema informatizado de dados relativos aos trabalhadores. Este sistema permite aos gestores pesquisar e controlar permanentemente o comportamento dos trabalhadores, no que se refere ao rendimento, absenteísmo, ocorrências disciplinares, freqüência aos serviços médicos e motivos da procura, requerimento de benefícios assistenciais etc. A informatização das atividades de gestão, por um lado, possibilita o aperfeiçoamento contínuo do sistema e, por outro, é importante instrumento de seleção controlada de trabalhadores.

Os programas técnicos preocupam-se com o estudo do cargo, a escolha do trabalhador certo para o cargo certo, o treinamento, a avaliação do desempenho e a combinação de mecanismos de premiação e punição para controlar o comportamento dos trabalhadores. O programa de recrutamento e seleção tem por finalidade selecionar mão-de-obra hígida, produtiva e disciplinada. No primeiro momento, os critérios que o fundamentam são produtividade e disciplina; os agentes da seleção são aqueles que diretamente controlam a quantidade e a qualidade do trabalho na lavoura: feitores, fiscais e administradores. No segundo momento, o critério básico é higidez suficiente para o desempenho do trabalho árduo na lavoura; o agente da seleção é o médico do trabalho que, em última instância, exclui aqueles trabalhadores que apresentam possibilidade de desenvolver patologias impeditivas da realização do trabalho em questão: hipertensão, doenças cardíacas, respiratórias e alérgicas, hérnias, comprometimentos na coluna vertebral e defeitos físicos exuberantes. 
Os treinamentos são peças fundamentais no processo de implantação dos programas de qualidade total e visam a motivar e envolver a todos na perseguição dos objetivos estratégicos da empresa: produtividade e qualidade. A reestruturação exige a redefinição dos objetivos e das metas ou, como dizem, da missão organizacional; o treinamento é o modo privilegiado de difusão e homogeneização desses objetivos e metas em todas as áreas da empresa. Um gerente de recursos humanos relatou que $80 \%$ das diretrizes estabelecidas no processo de redefinição da missão organizacional diziam respeito à sua área e que um levantamento das necessidades organizacionais demonstrou que um dos maiores problemas era a coexistência de uma grande diversidade de entendimentos sobre os objetivos da organização, o que resultava no funcionamento desarticulado das três grandes empresas que compõem a agroindústria: agrícola, industrial e administrativa. Os treinamentos são considerados importantes mecanismos de unificação do ideário organizacional, meio pelo qual se qualificam os trabalhadores para contribuírem no alcance dos objetivos, trabalhando de acordo com as normas e metas organizacionais. Eles não se restringem à mera transmissão/difusão de conteúdos técnicos relevantes para o bom desempenho da função; também procuram, permanentemente, promover mudanças comportamentais nos trabalhadores.

No setor industrial, o treinamento tanto tem sido do tipo formal, contabilizado em horas/homem $/ \mathrm{mês}^{(3)}$, como também é contínuo e incorporado no cotidiano da produção, mediante a constituição dos chamados grupos de ação corretiva e melhoria contínua e da implantação de programas como o $5 \mathrm{~S}^{(4)}$, por exemplo. $\mathrm{O}$ objetivo dos treinamentos e dos programas é, por um lado, difundir e harmonizar as metas organizacionais e, por outro, motivar e envolver a todos na perseguição dos objetivos comuns, desenvolvendo, principalmente, a capacidade de ter iniciativa para o trabalho.

Uma das conseqüências negativas da utilização dessas técnicas gerenciais para os trabalhadores é a intensificação do ritmo de trabalho porque, além das tarefas rotineiras da produção, os trabalhadores passam a se preocupar também com a limpeza e a conservação do ambiente de trabalho. Um membro de um dos grupos de melhoria contínua declarou que, na sua opinião, o $5 \mathrm{~S}$ é um programa que motiva a pessoa para o trabalho: "você vê, as moças de lá querem limpar, querendo ver aquele negócio [o setor de empacotamento de açúcar] limpo. Nunca tiveram motivação para isto" (engenheiro de segurança). Segundo o entrevistado, no setor em exame, as funcionárias, por iniciativa própria, reorganizaram o trabalho de tal modo que algumas se prontificaram para pintar corrimãos de escadas, concertar e limpar pequenas máquinas e instrumentos de trabalho nos momentos de ociosidade.

Outra possível conseqüência negativa para os trabalhadores é que pode ocorrer a extensão dos comportamentos aprendidos na empresa para a sua própria casa, 
no âmbito da convivência mais pessoal e familiar, ou seja, no âmbito das suas relações mais subjetivas. Neste sentido, outro membro do grupo de melhoria contínua desta empresa declarou:

"a gente está tentando abrir a cabeça do funcionário da importância desse trabalho até mesmo dentro de casa, porque eu sei que o nosso funcionário é assim [desmotivado] porque ele é assim dentro de casa [...] às vezes eu faço visitas domiciliares [como assistente social da empresa]; então você conhece a residência, você vai até a fonte do mesmo; logicamente você sabe que da mesma forma que ele é no trabalho ele é em casa [...] Por isso nós precisamos começar um trabalho de base, [de conscientização] da importância, do conforto que gera, dos retornos desse trabalho" (assistente social).

É evidente o conteúdo de tecnologia disciplinar que possuem esses programas de racionalização e intensificação do ritmo de trabalho e suas técnicas gerenciais. Eles lembram muito a criação dos denominados Departamentos de Beleza do Trabalho, criados na Alemanha na década de trinta e que, segundo Heloani (1996, p. 57, grifo no original), objetivavam a higienização e o embelezamento do ambiente de trabalho como forma de "difundir mecanismos docilizadores na percepção do trabalhador. Ou melhor: objetivava o aumento da produtividade em retribuição aos benefícios recebidos".

No setor rural, geralmente o denominado treinamento é apenas uma reunião destinada a integrar os trabalhadores à empresa, apresentando-lhes as normas básicas do seu funcionamento. O objetivo específico é diminuir os índices de absenteísmo, uma vez que este é um dos principais fatores que influem no rendimento do trabalho rural. Para inibir o absenteísmo rural, utilizam-se instrumentos pedagógicos, como cartazes e painéis, que contêm tabelas demonstrativas de perdas salariais e direitos trabalhistas, na tentativa de provar que as faltas acarretam prejuízo monetário ao trabalhador. O sistema informatizado de dados sobre os trabalhadores auxilia na identificação dos faltosos, apontando o motivo das ausências. Como a grande maioria das faltas é justificada via apresentação de atestado médico, pois esta é uma das estratégias dos trabalhadores para enfrentar o desgaste provocado pela atividade penosa com prejuízo mínimo para o salário, o tema saúde e segurança no trabalho recebe atenção especial durante os treinamentos.

A saúde é entendida estritamente do ponto de vista da assistência médica. Esta é apresentada como direito; estabelecem-se as regras para o seu uso. O trabalhador é informado sobre como a empresa identifica os freqüentadores dos serviços de saúde que não são portadores de enfermidades impeditivas da realização do trabalho. Esta é uma forma de inibir a demanda por assistência médica, de educar o trabalhador para comparecer aos serviços de saúde apenas quando se encon- 
tram no limite da sua capacidade de tolerar os agravos das enfermidades, ou quando estas interferem no rendimento do trabalho. As empresas medem a higidez do trabalhador rural pela sua capacidade de permanecer ausente dos serviços de saúde.

Outro fator que contribui para elevar o absenteísmo são os acidentes de traba1ho. Entretanto, no treinamento, a apresentação das Normas Regulamentadoras do Trabalho Rural (NRRs), que dispõem sobre as regras mínimas de higiene e segurança nas frentes de trabalho rurais, é superficial. Na verdade, a abordagem dessas normas é pretexto para imposição do modo de trabalhar prescrito pelos técnicos, que visa à qualidade e ao máximo aproveitamento da matéria-prima em detrimento da saúde e da segurança do trabalhador. Além de prescrever o modo de trabalhar, os técnicos também identificam os riscos da atividade e decidem sobre a necessidade ou não do uso de equipamentos de proteção individual (EPI's). Os feitores fazem cumprir as determinações técnicas, aplicando penalidades aos infratores. Ao trabalhador não cabe nenhum papel na vigilância e no controle do processo de trabalho, na eliminação dos seus elementos nocivos à saúde.

O treinamento aborda ainda as regras para os rurícolas usufruírem dos benefícios assistenciais, que passam pelo bom comportamento diante dos chefes e colegas de turma e, principalmente, pelo cumprimento das metas de produção. Coloca-se também a necessidade de os trabalhadores observarem um conjunto de comportamentos de conteúdo moral, referentes à proibição de atitudes que podem gerar ócio ou violência (uso de armas, bebidas alcoólicas, respeito ao sexo oposto, por exemplo), e político, se referentes ao incentivo à participação nas organizações sindicais.

As mudanças também se fazem perceber no âmbito das relações sindicais. Depois dos acontecimentos de Guariba, em 1984 e 1985 (D'Incao, 1984; Ferrante, 1991; Alves, 1991), e os subseqüentes (Silva, 1995), não convém aos empregadores negar a existência das organizações sindicais rurais, principalmente na região de Ribeirão Preto, mesmo considerando as suas dificuldades para mobilizar e organizar a categoria. $\mathrm{O}$ mais sensato é administrar profissionalmente a existência dessas organizações e até antecipar-se a elas no trabalho de formar uma consciência mais adequada. Neste ponto, as empresas contrariam a orientação taylorista/fordista de ignorar e combater a organização sindical, e incentivam a participação dos trabalhadores nos sindicatos, mas desde que os seus projetos e práticas sejam isentos de conteúdos contrários aos da empresa. Os sindicatos apenas são reconhecidos pelas empresas quando pactuam e se harmonizam com os objetivos empresariais, desempenhando funções predominantemente assistencialistas e paternalistas. Isto é, quando o sindicato se limita a ser um parceiro da empresa na concessão de alguns benefícios sociais que ajudem na reprodução adequada dos trabalhadores. 
Acima de tudo, esta estratégia empresarial no campo das relações sindicais permite harmonizar a convivência da empresa com os sindicatos e manter o comando da gerência sobre os trabalhadores. A manutenção de boas relações com os sindicalistas ajuda a diminuir as resistências e facilita a introdução das mudanças necessárias no processo produtivo. Assim, a empresa consegue, com o apoio do sindicato, a flexibilidade necessária para sobreviver e ampliar-se.

\section{Consideraçōes Finals}

Em síntese, os casos estudados permitem afirmar que a atual política de recursos humanos do setor sucroalcooleiro visa, sobretudo, a formar opinião pública favorável à reestruturação produtiva, ao mesmo tempo que envolve os trabalhadores na direção do alcance das metas organizacionais, no sentido de elevar os índices de produtividade com máxima qualidade e baixo custo. De modo geral, a uma política elaborada com base em um discurso científico, aparentemente consensual e pretensamente humanístico e participativo, contrapõe-se uma prática organizacional racionalista, que busca a produtividade e a qualidade.

A política de recursos humanos, apesar de incorporar um discurso humanístico e participativo, não representa uma superação do tradicional modelo de gestão taylorista/fordista predominante no setor. Aos princípios e técnicas taylorista/ fordistas de organização da produção incorporam-se alguns princípios e técnicas do modelo gerencial da Escola de Relações Humanas, o ideário da qualidade total (tão abundante nos inúmeros manuais e receituários que têm sido publicados sobre o assunto) e, ainda, algumas técnicas do chamado modelo japonês (Hirata, 1993) para redirecionar a gestão de recursos humanos no sentido de obter produtividade, qualidade e redução de custos. Na prática, ela não se traduz em melhoria real na qualidade de vida dos trabalhadores rurais. Pelo contrário, por tratar diferenciadamente os trabalhadores, conforme a modalidade contratual (diretamente contratados e subcontratados) e/ou conforme o desempenho individual, ela contribui para dificultar o processo de mobilização e organização da categoria para reivindicar os seus direitos em geral, especialmente em relação à saúde e segurança no trabalho. As ações empresariais desenvolvidas nas áreas da saúde e segurança no trabalho tornam-se instrumentos privilegiados de controle e de adequação do trabalho às exigências do processo produtivo. Elas derivam do modelo tradicional da medicina do trabalho e contribuem para criar representações sobre saúde e segurança no trabalho que convém aos interesses das empresas. Ao mesmo tempo que procuram preservar os trabalhadores, compensando, minimamente, os efeitos danosos causados pelas novas formas de organização da produção, 
criam novos hábitos e modos de vida adaptados às necessidades da produção. $\mathrm{O}$ que está em questão é a produtividade e a qualidade do trabalho e não a qualidade de vida dos trabalhadores.

Este modo de gestão dos recursos humanos dificulta o processo organizativo dos trabalhadores rurais, porque os divide na negociação e luta pela defesa dos seus interesses. De um lado, os diretamente contratados, beneficiados pela política de benefícios sociais, afastam-se das formas de organização coletiva e passam a lutar individualmente pela preservação do emprego; do outro lado, encontramse aqueles que, excluídos da produção e/ou contratados indiretamente, ainda lutam pelo cumprimento de direitos elementares como registro em carteira e remuneração mínima. Pode-se afirmar que a política de gestão constitui o principal recurso para o desenvolvimento de uma proposta pedagógica que, por um lado, visa à qualificação técnica e, por outro, à desqualificação político-organizativa dos trabalhadores. Assim, a política de gestão de recursos humanos do setor sucroalcooleiro em muito contribui para que os trabalhadores não reconheçam a saúde como processo social, mediado também por questões de ordem econômica e política, e um direito básico de cidadania. Eles tratam a saúde como questão estritamente biológica, individual e curativa, isenta de relações com seus modos específicos de trabalhar e viver, apesar de ser o próprio corpo o único bem que possuem.

\section{Notas}

${ }^{1}$ Considera-se que a macrorregião canavieira de Ribeirão Preto é formada pelas regiões administrativas de Barretos, Central, Franca e Ribeirão Preto.

${ }^{2}$ A Escola de Relações Humanas é um modelo gerencial que surgiu na década de vinte; em linhas gerais, tem como princípio básico a valorização do homem e das relações grupais no ambiente empresarial. O objetivo maior é o de criar clima harmônico e favorável ao bem-estar material e social e conduzir os membros da organização para a auto-realização. Tratemberg (1989) considera retórico o humanismo apregoado por este modelo de gestão. Primeiramente, porque o administrador recorre à sua autoridade para garantir a produtividade; em segundo lugar, porque a metodologia utilizada, essencialmente behaviorista, procura adaptar o indivíduo ao meio, sem que este seja qualitativamente transformado. O referido autor alega que, por meio de técnicas nãodiretivas e catárticas, procura-se provocar a exteriorização das tensões individuais internas para eliminar ou, pelo menos, aliviar os conflitos organizacionais. Com isto, facilita-se a comunicação e a integração dos diferentes níveis hierárquicos e obtêm-se dos indivíduos atitudes de cooperação e solidariedade e, sobretudo, de aceitação da autoridade e das diretrizes administrativas. Assim, no interior da empresa, as relações sociais transformam-se em pessoais e ignoram-se aquelas que se dão fora do seu âmbito político (com o sindicato, por exemplo), no sentido de que todos os conflitos e os problemas emergentes podem ser solucionados sem a interferência de outros. 
${ }^{3} \mathrm{O}$ número de horas/treinamento/homem de uma das empresas estudadas foi de 8, em média, entre os meses de outubro de 1995 e fevereiro de 1996. Nota-se que não há registro da ocorrência de treinamentos entre março e setembro de 1996, período do ano que coincide com a época da safra.

${ }^{4} \mathrm{O} 5 \mathrm{~S}$ é um programa que objetiva reorganizar o ambiente produtivo como forma de iniciar um processo de mudança comportamental nos trabalhadores. Os Ss significam senso de organização, de ordem, de limpeza, de saúde e de auto-disciplina e se traduzem em um conjunto de regras que devem ser implementadas gradativamente e obedecidas no dia-a dia de trabalho. Tanto a proposição como o controle e a fiscalização do cumprimento das novas regras de ordenamento e conservação do espaço de trabalho são realizadas pelos próprios trabalhadores, através da formação de equipes compostas por elementos de diferentes setores da empresa, os denominados grupos de melhoria contínua, comitê guia, comitê corporativo etc.

\section{REFERÊNCIAS BIBLIOGRÁFICAS}

ALESSI, N. P.;

SCOPINHO, R. A.

A saúde do trabalhador do corte da cana-de-açúcar. In: ALESI, N. P. et al. (Orgs.). Saúde e trabalho no Sistema Único de Saúde. São Paulo : Hucitec, 1994. p. 121151.

ALVES, F. J. C.

Progresso técnico na agricultura : mudança na organização e no processo de trabalho - o caso da canade-açúcar. In: ESCOLA SINDICAL 7 DE OUTUBRO (Org.). Outras falas... em processo de trabalho. Belo Horizonte : Editora Escola Sindical 7 de Outubro, 1992. p. 117-145.

ANUÁRIO JORNALCANA.

Safra 98/99. v. Centro/Sul, 1999.
CABRAL, H. H.

A assistência social na agroindústria do açúcar e do álcool. São Paulo, 1990. Dissertação (Mestrado) - Pontifícia Universidade Católica de São Paulo.

CORTÉZ, K. V. D.

\section{Inovações tecnológicas e mudan-} ças na organização do trabalho : o surgimento de um novo tipo de trabalhador na cultura canavieira na região de Ribeirão Preto. São Carlos, 1993. Dissertação (Mestrado em Engenharia de Produção) - Departamento de Engenharia de Produção, Universidade Federal de São Carlos.

D'INCAO, M. C.

A questão do bóia-fria. São Paulo : Editora Brasiliense, 1984. 
EID, F.

Economie de rente et agroindustrie du sucre et de l'alcool au Brésil. Amiens, 1994. Thèse (Doctorat) - Université de Picardie Jules Verne.

EID, F. et al.

Automação microeletrônica e impactos na organização do trabalho na indústria sucroalcooleira. Revista Produto \& Produção, v. 2, n. 2, p. 63-68, 1998.

FERRANTE, V. L. S. B.

A chama verde dos canaviais : uma história de luta dos bóias-frias. Araraquara, 1991. Tese (Livre Docência) - Faculdade de Filosofia Ciências e Letras, Universidade do Estado de São Paulo.

GPA - GUIA DE PRODUTORES DE AÇÚCAR E ÁLCOOL.

Safra 93/94 - Região Centro-Sul. 8. ed. Franca : EPK, 1994.

HELOANI, J. R.

Organização do trabalho e administração : uma visão multidisciplinar. 2. ed. São Paulo : Cortez, 1996.

\section{KUENZER, A. Z.}

Pedagogia da fábrica : as relações de produção e a educação do trabalhador. 3. ed. São Paulo : Cortez, 1989.
LAURELL, A. C.;

NORIEGA, M.

Processo de produção e saúde : trabalho e desgaste operário. São Paulo : Hucitec, 1989.

MACHADO, L. R. DE S.

TQC : forjando a cultura do controle pela cooptação dos trabalhadores. In: FIDALGO, F. S.; MACHADO, L. R. DE S. (Orgs.). Controle da qualidade total : uma nova pedagogia do capital. Belo Horizonte : Movimento Cultura Marxista, 1994. p. 42-52.

NOGUEIRA, E. A. (Coord.).

Estatística de salários agrícolas no Estado de São Paulo. São Paulo : Instituto de Economia Agrícola, 1992.

PINHEIRO, S. A.

Estudo do processo trabalhodesgaste em trabalhadores de destilaria de álcool. Ribeirão Preto, 1992. Tese (Doutorado) - Faculdade de Medicina de Ribeirão Preto, Universidade de São Paulo.

SCOPINHO, R. A.

Pedagogia empresarial de controle do trabalho e saúde do trabalhador : o caso de uma usinadestilaria da região de Ribeirão Preto. São Carlos, 1995. Dissertação (Mestrado) - Centro de Educação e Ciências Humanas, Universidade Federal de São Carlos. 
SCOPINHO, R. A.;

VALARELLI, L. L. (Orgs.).

Modernização e impactos sociais : o caso da agroindústria sucroalcooleira da região de Ribeirão Preto (SP). Rio de Janeiro: Fase, 1995.

SCOPINHO, R. A. et al.

Novas tecnologias e saúde do trabalhador : a mecanização do corte da cana-de-açúcar. Cadernos de Saúde Pública, v. 15, n. 1, 1999.
TRATEMBERG, M.

Administração, poder e ideologia. 2. ed. São Paulo : Cortez, 1989.

VEIGA FILHO, A. DE A. et al.

Análise da mecanização do corte da cana-de-açúcar no Estado de São Paulo. Informações Econômicas, v. 24 , n. 10 , p. 43-58, 1994. 